\title{
Sporamin suppresses growth of human esophageal squamous cell carcinoma cells by inhibition of NF- $\kappa B$ via an AKT-independent pathway
}

\author{
CUI-JUAN QIAN, YONG-XIAO QI, XIAO-YING CHEN, JU-PING ZENG and JUN YAO \\ Institute of Tumor, School of Medicine, Taizhou University, Taizhou, Zhejiang 318000, P.R. China
}

Received September 11, 2016; Accepted June 15, 2017

DOI: $10.3892 / \mathrm{mmr} .2017 .7772$

\begin{abstract}
The aim of the present study was to determine whether sporamin, a trypsin inhibitor, suppresses the growth of human esophageal squamous cell carcinoma (ESCC) cells in vitro. Sporamin treatment led to the suppression of viability and proliferation of human ESCC cell lines, EC9706 and EC109, as determined by MTT and $\left[{ }^{3} \mathrm{H}\right]$ thymidine incorporation assays, respectively. Flow cytometry and fluorescence microscopy demonstrated that sporamin significantly induced apoptosis in EC9706 and EC109 cells. Western blotting demonstrated that sporamin downregulated the expression of Bcl-2 and Bcl-2 like 1, and upregulated the expression of Bcl-2-associated X in EC9706 and EC109 cells. In addition, marked inhibition of nuclear factor (NF)- $\kappa \mathrm{B}$ activation was observed in sporamin-treated EC9706 and EC109 cells by an electrophoretic mobility shift assay. Sporamin treatment also resulted in reduced expression levels of phosphorylated (p)-NF- $\kappa$ B inhibitor $\alpha$ and nuclear NF- $\kappa$ B p65. However, the expression levels of p-protein inase (AKT) and its downstream target, p-p70 S6 kinase, were not markedly altered following sporamin treatment. In conclusion, sporamin may suppress the growth of human ESCC cells via NF- $\mathrm{BB}$-dependent and AKT-independent mechanisms and may act as a promising natural therapeutic agent for the treatment of human ESCC.
\end{abstract}

\section{Introduction}

Esophageal cancer (EC) is the sixth most common cause of cancer-associated deaths worldwide (1) and esophageal squamous cell carcinoma (ESCC) accounts for $70 \%$ of EC cases (2).

Correspondence to: Professor Jun Yao, Institute of Tumor, School of Medicine, Taizhou University, 1139 Shifu Road, Jiaojiang, Taizhou, Zhejiang 318000, P.R. China

E-mail: yaojuntzu@yeah.net

Abbreviations: EC, esophageal cancer; ESCC, esophageal squamous cell carcinoma

Key words: sporamin, nuclear factor- $\mathrm{B}$, protein kinase $\mathrm{B}$, esophageal squamous cell carcinoma
Once diagnosed, the prognosis is poor in the majority of patients with advanced EC, regardless of the stage (3). Despite advances in the traditional treatments for EC, the mortality from EC has not improved greatly (4). Therefore, it is necessary to develop novel therapeutic methods that may improve the survival rate of patients with advanced EC.

Sporamin, a trypsin inhibitor, is the primary soluble storage protein in sweet potato tuberous roots, and has been identified as an antitumor agent that induces antitumor effects in certain types of tumor cells $(5,6)$. However, to the best of our knowledge, the mechanisms underlying its diverse biological effects have not previously been investigated in ESCC cells. Therefore, the effects of sporamin on cell viability, cell proliferation activity and apoptosis were investigated in EC9706 and EC109 human ESCC cell lines.

Nuclear factor $(\mathrm{NF})-\kappa \mathrm{B}$ has been associated with the promotion of esophageal tumorigenesis by protecting tumor cells from cell death (7). AKT is a protein kinase that transduces signals from oncogenes or growth factors, such as epidermal growth factor receptor (EGFR), to downstream targets in tumor cells (8). NF- $\kappa \mathrm{B}$ signaling may be activated via the AKT signaling pathway (9). Therefore, in the present study, the effects and underlying mechanisms of sporamin

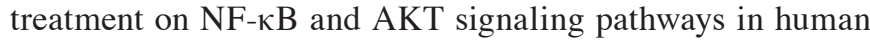
ESCC cells were investigated.

The authors' previous studies have demonstrated that sporamin treatment suppresses the growth of human tongue carcinoma cells in vitro (6). However, the detailed effects and mechanisms of sporamin on ESCC cells have not been well characterized. To improve the understanding of the effects and underlying mechanisms of sporamin on ESCC cells, an MTT assay, $\left[{ }^{3} \mathrm{H}\right]$ thymidine incorporation assay, morphological and flow cytometry analysis, western blotting and electrophoretic mobility shift assay (EMSA) were performed in the present study.

\section{Materials and methods}

Cell line and materials. EC109 and EC9706 cells (Type Culture Collection of the Chinese Academy of Sciences, Shanghai, China), which are well and poorly differentiated human ESCC cell lines, respectively, were cultured in Dulbecco's modified Eagle's medium (DMEM; Gibco; Thermo Fisher Scientific, Inc., Waltham, MA, USA) 
A

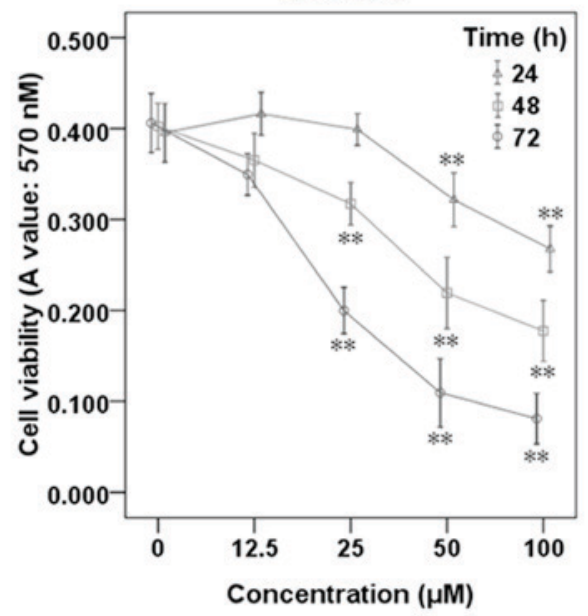

B

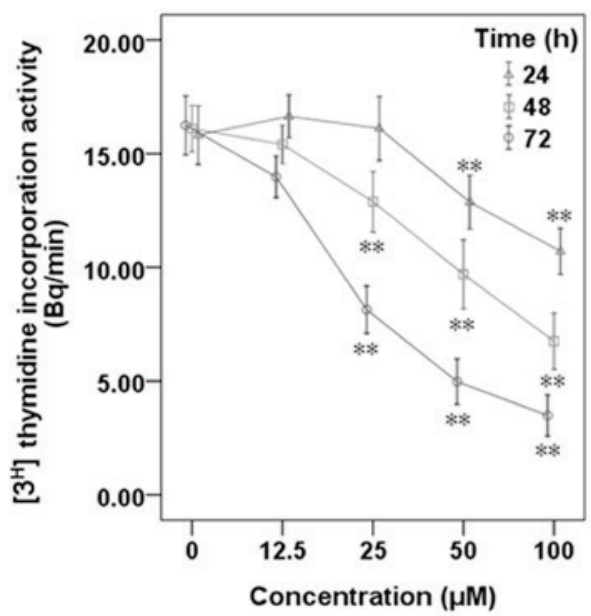

EC109

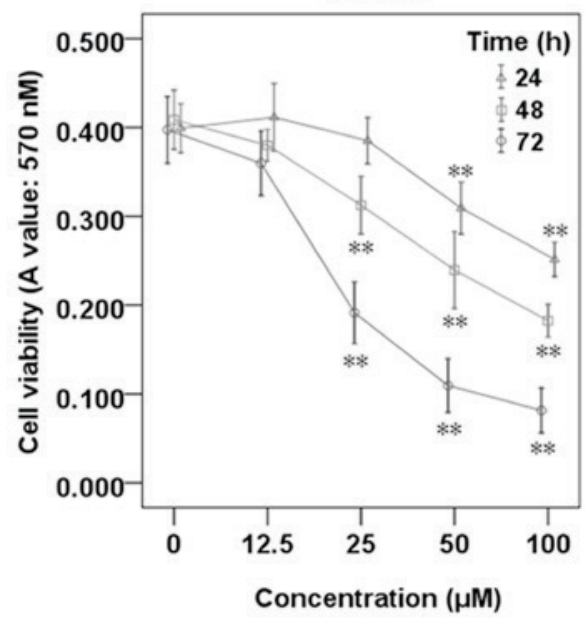

EC109

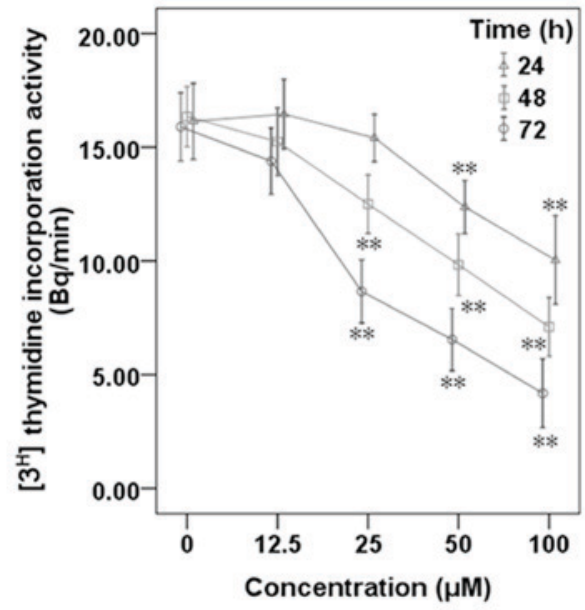

Figure 1. Concentration- and time-dependent effects of sporamin on cell viability and proliferation activity in esophageal squamous cell carcinoma cells. EC9706 and EC109 cells were incubated in the absence or presence of 12.5, 25, 50 and $100 \mu \mathrm{M}$ sporamin for 24, 48 and $72 \mathrm{~h}$. (A) Cell viability was determined by an MTT assay. (B) Cell proliferation was determined using a $\left[{ }^{3} \mathrm{H}\right]$ thymidine incorporation assay. Data are presented as mean \pm standard deviation ( $\mathrm{n}=4$ independent experiments). Data are exhibited as the mean \pm standard deviation of the mean. $n=4$ experiments, ${ }^{* *} \mathrm{P}<0.01$ vs. Control. A value, absorbance value.

supplemented with $10 \%$ fetal bovine serum (FBS), $10 \mathrm{U} / \mathrm{ml}$ penicillin and $10 \mu \mathrm{g} / \mathrm{ml}$ streptomycin at $37^{\circ} \mathrm{C}$ and $5 \% \mathrm{CO}_{2}$. Sporamin, a primary soluble protein in sweet potatoes with trypsin inhibitory activity, was purified from fresh sweet potato tuberous roots (Ipomoea batatas cv. Tainong 57; Hangzhou Lianhua Huashang Group Co., Zhejiang, China), as described previously (6). The primary antibodies against Bcl-2 (catalog no. sc-509), Bcl-2 like 1 (Bcl-XL; catalog no. sc-7122), Bcl-2-associated X (Bax; catalog no. sc-23959) and NF-кB p65 (catalog no. sc-8008) were purchased from Santa Cruz Biotechnology, Inc. (Dallas, TX, USA). AKT (catalog no. 9272), phosphorylated (p)-AKT (Thr308; catalog no. 4056), p70 S6 kinase (catalog no. 9202), p-p70 S6 kinase (Thr421/Ser424; catalog no. 9204), NF-кB inhibitor $\alpha$ (ІкB $\alpha$; catalog no. 9242) and $\mathrm{p}-\mathrm{I} \kappa \mathrm{B} \alpha$ (Ser32; catalog no. 2859) primary antibodies were purchased from Cell Signaling Technology, Inc. (Danvers, MA, USA), and tubulin (catalog no. ab59680), histone (H)2A (catalog no. ab13923) and $\beta$-actin (catalog no. ab8227) primary antibodies were purchased from Abcam (Cambridge, UK).
MTT assay. The in vitro cell viability of EC109 and EC9706 cells treated with sporamin was measured using the MTT assay. A total of $1 \times 10^{3}$ cells/well were cultured in 96 -well plates and incubated with $0,12.5,25,50$ or $100 \mu \mathrm{M}$ sporamin for 24,48 or $72 \mathrm{~h}$ at $37^{\circ} \mathrm{C}$. Dimethyl sulfoxide (DMSO) was cells treated with as a control instead of sporamin. Medium was discarded and wells were replaced with $100 \mu \mathrm{l}$ fresh medium containing $10 \%$ MTT solution (5 mg/ml stock) at $37^{\circ} \mathrm{C}$ for $4 \mathrm{~h}, 100 \mu \mathrm{l}$ DMSO was subsequently added to each well before agitating the plates at room temperature for $10 \mathrm{~min}$. Colorimetric determination of MTT reduction was determined at a wavelength of $570 \mathrm{~nm}$ using a microplate ELISA reader (Bio-Rad Laboratories, Inc., Hercules, CA, USA).

$\left[{ }^{3} \mathrm{H}\right]$ thymidine incorporation assay. The in vitro cell proliferation activity of EC109 and EC9706 cells treated with sporamin was measured by a $\left[{ }^{3} \mathrm{H}\right]$ thymidine incorporation assay (Sigma-Aldrich; Merck KGaA, Darmstadt, Germany). A total of $2.5 \times 10^{5}$ cells/well were cultured in 24-well plates in DMEM with $10 \%$ dialyzed and charcoal-stripped FBS. 

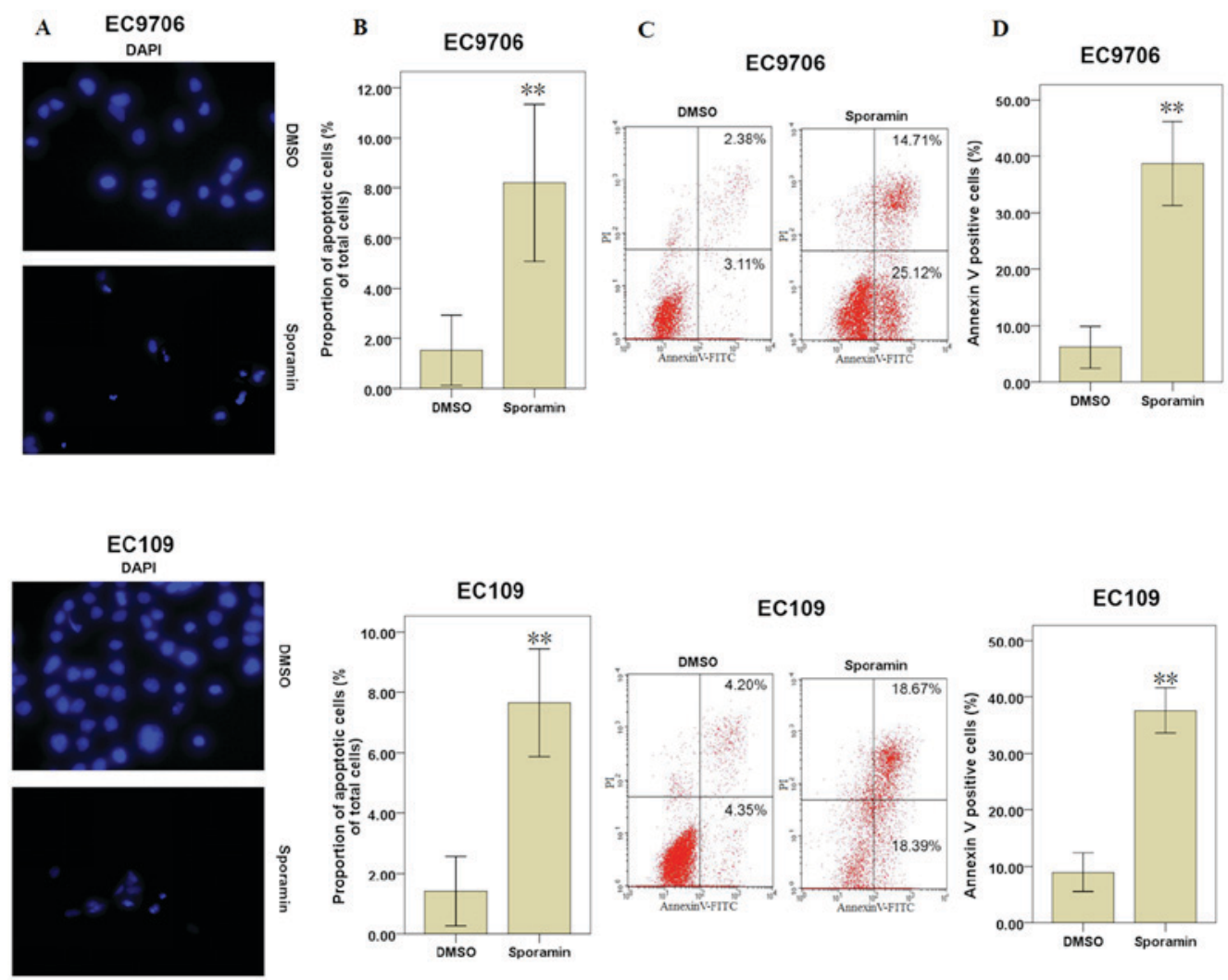

Figure 2. Effects of sporamin on apoptosis of esophageal squamous cell carcinoma cells. EC9706 and EC109 cells were treated with $25 \mu \mathrm{M}$ sporamin or DMSO for $48 \mathrm{~h}$. (A) Cells were stained with DAPI and images were captured using fluorescence microscopy. Condensed and fragmented nuclei were observed in sporamin-treated cells (magnification, x200). (B) Percentage of apoptotic cells was determined by direct apoptotic cell counting following DAPI staining. (C) Percentages of apoptotic cells were analyzed by flow cytometry following annexin V-FITC/PI staining. (D) Histograms of the percentage of apoptotic cells following annexin V-FITC/PI staining. Data are presented as the mean \pm standard deviation ( $\mathrm{n}=4$ independent experiments). ${ }^{* * *} \mathrm{P}<0.01 \mathrm{vs}$. DMSO. DMSO, dimethyl sulfoxide; FITC, fluorescein isothiocyanate; PI, propidium iodide.

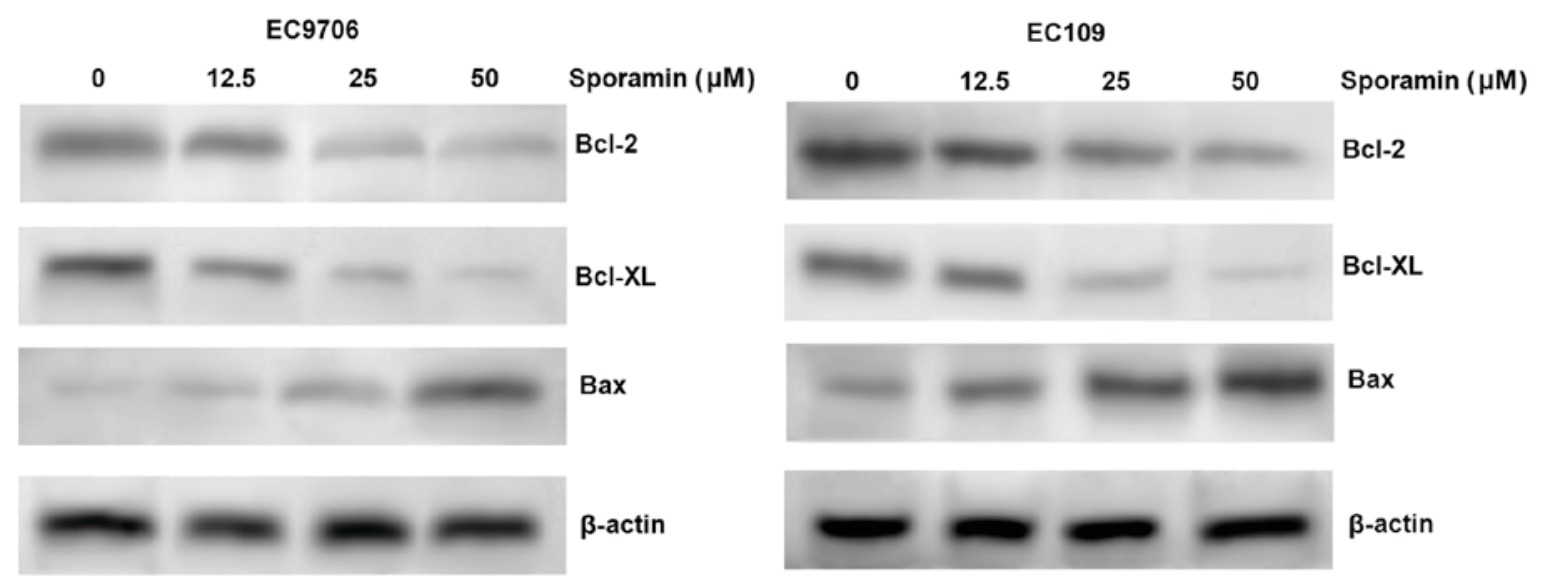

Figure 3. Effects of sporamin treatment on the expression levels of Bcl-2, Bcl-XL and Bax in esophageal squamous cell carcinoma cells. The protein expressions levels of Bcl-2, Bcl-XL and Bax in EC9706 and EC109 cells were detected by western blotting following treatment with $12.5,25$ and $50 \mu \mathrm{M}$ sporamin for 48 h. Bcl-XL, Bcl-2 like 1 ; Bax, Bcl-2-associated X.

When cells reached $80 \%$ confluence, the cultures were rinsed in phenol-free DMEM medium and incubated with $0,12.5,25$, 50 or $100 \mu \mathrm{M}$ sporamin in phenol-free and serum-free DMEM for 24,48 and $72 \mathrm{~h} .\left[{ }^{3} \mathrm{H}\right]$ thymidine $\left(1.35 \times 10^{4} \mathrm{~Bq} / \mathrm{l}\right)$ was added and cultured with cells for a further $12 \mathrm{~h}$ at $37^{\circ} \mathrm{C}$. Subsequently, the supernatant was aspirated and excess $\left[{ }^{3} \mathrm{H}\right]$ thymidine was removed by washing with PBS. Finally, $0.2 \mathrm{~mol} / 1 \mathrm{NaOH}$ was added at $37^{\circ} \mathrm{C}$ and radioactivity $\left(\left[{ }^{3} \mathrm{H}\right]\right.$ thymidine incorporation activity) was determined by scintillation counting (LS6500; Beckman Instruments, Inc., Fullerton, CA, USA).

Morphological determination and quantification of apoptosis. Cells were cultured in 12 -well plates at a density of $2 \times 10^{4}$ cells per well and incubated with $25 \mu \mathrm{M}$ sporamin or DMSO for 


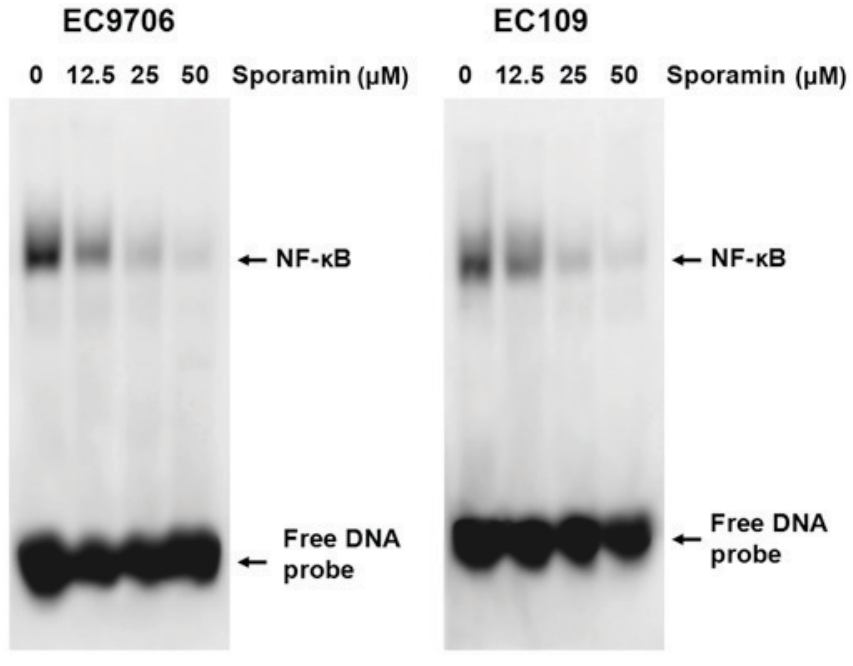

Figure 4. Effects of sporamin on NF-кB DNA-binding activity in esophageal squamous cell carcinoma cells. Sporamin inhibited NF- $\kappa$ B DNA-binding activity in a concentration-dependent manner in EC9706 and EC109 cells. Nuclear extracts from EC9706 and EC109 cells incubated with 0, 12.5, 25 and $50 \mu \mathrm{M}$ sporamin for $48 \mathrm{~h}$ were subjected to electrophoretic mobility

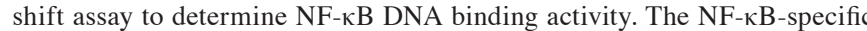
complex and the free DNA probe are indicated (arrows). NF- $\kappa \mathrm{B}$, nuclear factor- $\mathrm{\kappa} \mathrm{B}$.

$48 \mathrm{~h}$ at $37^{\circ} \mathrm{C}$. Cells were then fixed with $4 \%$ cold paraformaldehyde at $4^{\circ} \mathrm{C}$ for $15 \mathrm{~min}(\mathrm{pH} \mathrm{7.4)}$ and stained with $0.5 \mu \mathrm{g} / \mathrm{ml}$ DAPI (Sigma-Aldrich, Merck KGaA, Darmstadt, Germany) for $5 \mathrm{~min}$ at room temperature. The cells were subsequently visualized under a fluorescence microscope (model DMI4000B; Olympus Corporation, Tokyo, Japan) using a 360-370 nm excitation light and a 420-460 nm emission filter. Cells undergoing apoptosis exhibit profound structural alterations, including apoptotic chromatin condensation, nuclear envelope shrinkage and fragmentation. Apoptotic morphological changes in the nucleus were distinguished from intact nuclei and counted, and the percentages were subsequently calculated. A total of six randomly chosen fields of view were examined with a minimum number of 500 cells scored in each condition.

Flow cytometry analysis for apoptosis. Apoptosis was measured using an Annexin V-Fluorescein Isothiocyanate (FITC)/Propidium Iodide (PI) Apoptosis Detection kit (BD Biosciences, Franklin Lakes, NJ, USA) according to the manufacturer's protocol. Briefly, $1.5 \times 10^{6}$ cells/well were incubated with $25 \mu \mathrm{M}$ sporamin or DMSO for $48 \mathrm{~h}$ at $37^{\circ} \mathrm{C}$. Both attached and floating cells were pooled, pelleted by centrifugation at $100 \mathrm{x} \mathrm{g}$ for $5 \mathrm{~min}, 4^{\circ} \mathrm{C}$, washed twice with cold PBS and $1 \times 10^{6}$ cells $/ \mathrm{ml}$ were resuspended in $1 \mathrm{X}$ binding buffer [10 mM hydroxyethyl piperazine ethanesulfonic acid, ( $\mathrm{pH} 7.4)$, $2.5 \mathrm{mM} \mathrm{CaCl}_{2}$, and $140 \mathrm{mM} \mathrm{NaOH}$ ]. A total of $1 \times 10^{5}$ cells were transferred to a 5-ml tube and stained with $5 \mu \mathrm{l}$ annexin V-FITC and $5 \mu \mathrm{l}$ PI for $15 \mathrm{~min}$ at room temperature in the dark. Finally, $400 \mu \mathrm{l} 1 \mathrm{X}$ binding buffer was added to each tube and apoptosis was determined using a BD FACSCanto II flow cytometer with BD Accuri ${ }^{\mathrm{TM}}$ C6 software (BD Biosciences, San Jose, CA, USA).

Western blotting. Total protein was extracted from treated cells using M-Per Mammalian Protein Extraction reagent (Pierce;
Thermo Fisher Scientific, Inc.) according to the manufacturer's protocol. Nuclear fractions were prepared using a Nuclear Protein Extraction kit (Beyotime Institute of Biotechnology, Haimen, China) according to the manufacturer's protocol. The protein concentrations were determined using a Bradford assay. Cell protein extracts were either used immediately or stored at $-70^{\circ} \mathrm{C}$.

For SDS-PAGE, a total of $20 \mu \mathrm{g}$ protein was loaded into each well of $10-12 \%$ gel and electrophoresed at $98 \mathrm{~V}$. Proteins on the gel were transferred onto a polyvinylidene fluoride membrane by wet electrotransfer for $2 \mathrm{~h}$. The membrane was blocked in 5\% bovine serum albumin (Sigma-Aldrich; Merck KGaA) in TBS containing $0.1 \%$ Tween-20 at room temperature for $90 \mathrm{~min}$. The primary antibodies (all used at a 1:200

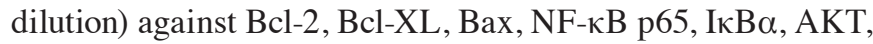
p70 S6 kinase, p-IкB $\alpha$ (Ser32), p-AKT (Thr308), p-p70 S6 kinase (Thr421/Ser424), tubulin, H2A and $\beta$-actin were added separately and incubated with the membrane overnight at $4^{\circ} \mathrm{C}$. The membranes were subsequently washed three times with TBS/0.1\% Tween-20. The following day, membranes were incubated with horseradish peroxidase-conjugated anti-rabbit (1:2,000; cat. no. 7074; Cell Signaling Technology, Inc.), anti-mouse (1:2,000; cat. no. 7076; Cell Signaling Technology, Inc.), and anti-goat (1:2,000; cat. no. sc-2350; Santa Cruz Biotechnology) immunoglobulin $\mathrm{G}$ secondary antibodies. The membrane was subsequently washed four times with TBS/0.1\% Tween-20, 5 min per wash. All bands were visualized using Pierce ${ }^{\mathrm{TM}}$ enhanced chemiluminescence Western Blotting Substrate (Merck KGaA, Darmstadt, Germany) and scanned using an LAS-4000 imaging system (Fujifilm, Tokyo, Japan).

EMSA. For EMSA, cells were treated with $0,12.5,25$ or $50 \mu \mathrm{M}$ sporamin for $48 \mathrm{~h}$ at $37^{\circ} \mathrm{C}$. EMSA was performed using a commercial kit (Gel Shift Assay System; Promega Corporation, Madison, WI, USA) according to the manufacturer's protocol. Nuclear Protein Extraction kit (Beyotime Institute of Biotechnology, Haimen, China) was adopted to prepare nuclear fractions, according to the manufacturer's protocol. A bicinchoninic assay was used to determine the protein concentration. Nuclear protein $(2 \mu \mathrm{g})$ was preincubated in binding buffer [10 mM Tris- $\mathrm{Cl},(\mathrm{pH} 7.5), 50 \mathrm{mM}$ $\mathrm{NaCl}, 1 \mathrm{mM} \mathrm{MgCl}{ }_{2}, 0.5 \mathrm{mM}$ EDTA, $4 \%$ glycerol, $0.5 \mathrm{mM}$ DTT and $0.05 \mathrm{~g} / 1$ poly (deoxyinosinic deoxycytidylic acid)] for $15 \mathrm{~min}$ at room temperature. After addition of $1 \mu 1{ }^{32} \mathrm{P}$-labeled oligonucleotide probe $(1.75 \mathrm{pmol} / \mu \mathrm{l})$, the incubation was continued for $30 \mathrm{~min}$ at room temperature. The reaction was stopped by adding $1 \mu 1$ gel loading buffer and the mixture was subjected to $4 \%$ nondenaturing polyacrylamide gel electrophoresis in $0.5 \mathrm{X}$ Tris/Borate/EDTA buffer. The gel was vacuum-dried and exposed to X-ray film at $-70^{\circ} \mathrm{C}$. The dried gels were visualized by autoradiography using $\mathrm{X}$-ray film.

Statistical analysis. Data are presented as the mean \pm standard deviation. A one-way analysis of variance followed by Tukey's post hoc test, or student's t-test were used to compare differences between groups using SPSS version 18.0 software (SPSS Inc., Chicago, IL, USA). $\mathrm{P}<0.05$ was considered to indicate a statistically significant difference. 

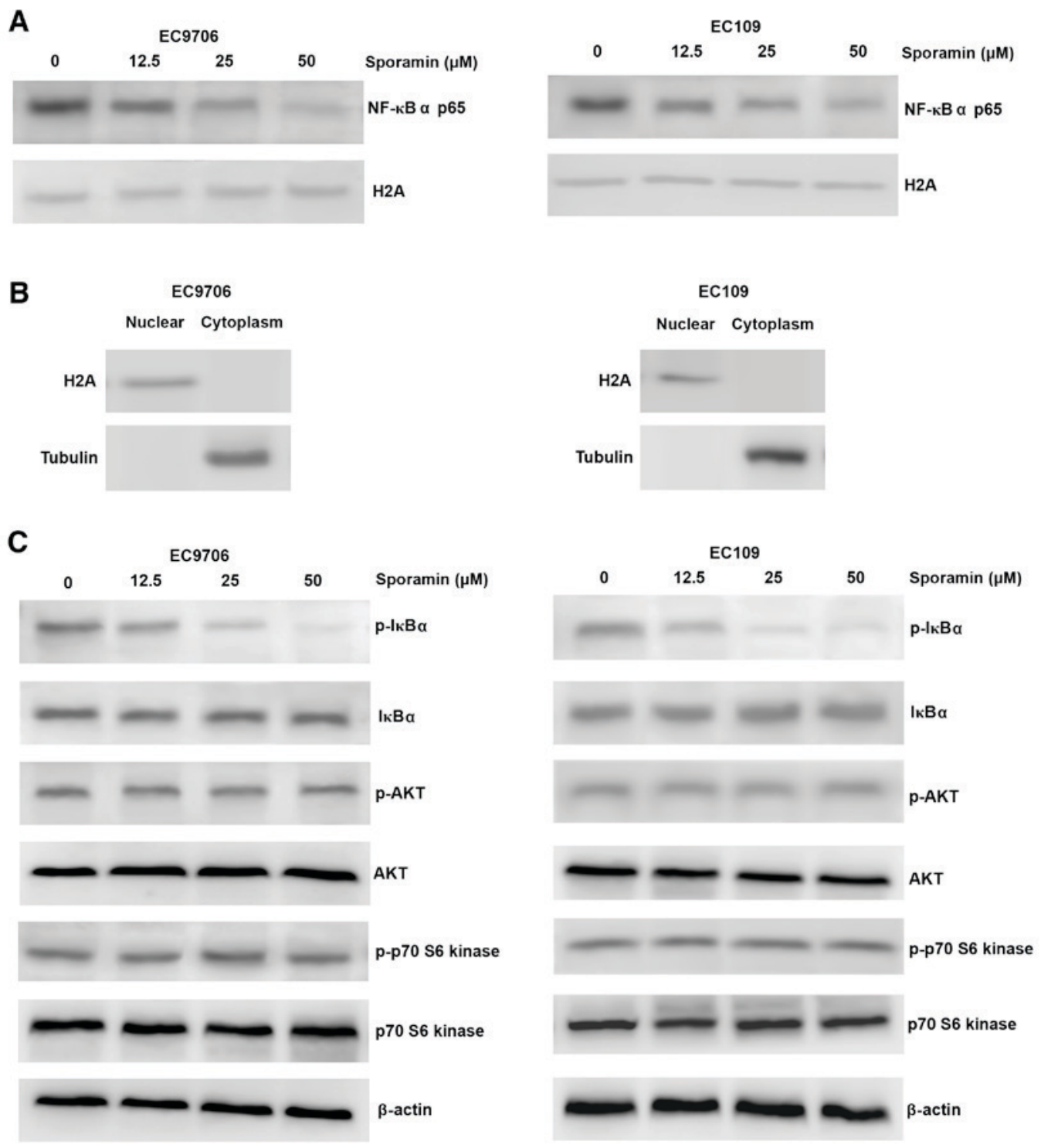

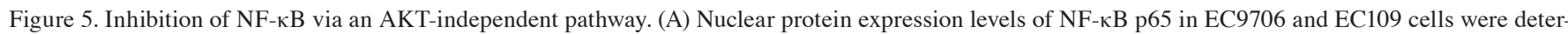
mined by western blotting. H2A protein levels were measured as a nuclear loading control. Tubulin and H2A were used as loading controls for the cytoplasmic and nuclear fractions, respectively. (B) The purity of the nuclear fraction was confirmed by western blotting of tubulin and H2A. (C) Cellular total protein levels of p-IкB $\alpha$ (Ser32), IкB $\alpha$, p-AKT (Thr308), AKT, p-p70 S6 kinase (Thr421/Ser424) and p70 S6 kinase in EC9706 and EC109 cells were also detected by

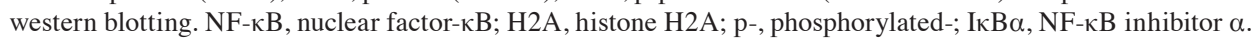

\section{Results}

Sporamin inhibits cell viability and proliferation activity in ESCC cells. To investigate the effects of sporamin on cell viability and the proliferation of ESCC cells, EC9706 and EC109 cells were treated with sporamin at increasing concentrations $(12.5,25,50$ and $100 \mu \mathrm{M})$ and for varying durations (24, 48 and $72 \mathrm{~h}$ ), and cell viability and proliferation were determined using an MTT assay (Fig. 1A) and a $\left[{ }^{3} \mathrm{H}\right]$ thymidine incorporation assay (Fig. 1B), respectively. The results demonstrated that sporamin significantly inhibited cell viability and proliferation activity in a concentration- and time-dependent manner.

Sporamin induces cell apoptosis in ESCC cells. When EC9706 and EC109 cells were treated with $25 \mu \mathrm{M}$ sporamin for $48 \mathrm{~h}$, the inhibition of cell viability and proliferation activity were significant. Therefore, cells were treated with $25 \mu \mathrm{M}$ sporamin for $48 \mathrm{~h}$ for further experiments. Apoptotic cells were examined under fluorescence microscopy following DAPI staining. Following exposure to sporamin, the cell volume reduced, the chromatin became condensed and the nuclei became fragmented, compared with DMSO-treated cells (Fig. 2A). Compared with DMSO-treated control cells, the percentage of apoptotic cells was increased significantly following sporamin treatment in EC9706 and EC109 cells (Fig. 2B).

As sporamin induced morphological changes associated with apoptosis at a concentration of $25 \mu \mathrm{M}$ for $48 \mathrm{~h}$, annexin $\mathrm{V}$ and PI staining was additionally performed to determine cell apoptosis. The results demonstrated that the percentages of apoptotic cells (annexin V positive cells) were increased significantly following culture with sporamin, compared with the DMSO control cells (Fig. 2C and D). These results 
indicate that sporamin may induce cell apoptosis in EC9706 and EC109 cells.

Sporamin induces the downregulation of Bcl-2 and Bcl-XL, and upregulation of Bax in ESCC cells. As Bcl-2, Bcl-XL and Bax are involved in the promotion of apoptosis, the expression levels of Bcl-2, Bcl-XL and Bax in EC9706 and EC109 cells were measured by western blotting, to identify the potential underlying molecular basis for the effects of sporamin on ESCC cells. The results indicated that sporamin inhibited the expression of the anti-apoptotic proteins, Bcl-2 and $\mathrm{Bcl}-\mathrm{XL}$, and induced the expression of the proapoptotic protein Bax, in a concentration-dependent manner in EC9706 and EC109 cells (Fig. 3). The results indicate that sporamin may induce apoptosis via the regulation of $\mathrm{Bcl}-2, \mathrm{Bcl}-\mathrm{XL}$ and Bax expression.

Sporamin inhibits $N F-\kappa B$ DNA-binding activity in ESCC cells. As Bcl-2 and Bcl-XL may be regulated by $\mathrm{NF}-\kappa \mathrm{B}$ (10), it was hypothesized that sporamin may mediate its effects by regulating $\mathrm{NF}-\kappa \mathrm{B}$. Therefore, nuclear extracts of EC9706 and EC109 cells treated with various concentrations of sporamin $(12.5,25$ and $50 \mu \mathrm{M})$ or control diluent were prepared and $\mathrm{NF}-\kappa \mathrm{B}$ DNA-binding activity was examined by EMSA. As demonstrated in Fig. 4, a marked reduction of $\mathrm{NF}-\kappa \mathrm{B}$ DNA-binding activity was observed in sporamin-treated cells in a concentration-dependent manner. These results indicate that sporamin may inhibit NF- $\mathrm{B}$ DNA-binding activity.

Sporamin inhibits $N F-\kappa B$ activation via an AKT-independent mechanism in ESCC cells. Treatment with sporamin resulted in reduced nuclear expression of NF- $\kappa \mathrm{B}$ p65 in a concentration-dependent manner in EC9706 and EC109 cells (Fig. 5A and $\mathrm{B})$. Consistently, there was a marked reduction in the expression levels of $\mathrm{p}-\mathrm{I} \kappa \mathrm{B} \alpha$ (Fig. 5C). However, the expression and phosphorylation levels of AKT, or its downstream target, p-p70 S6 kinase, were not altered following sporamin treatment (Fig. 5C). These results indicate that NF- $\kappa$ B inhibition by sporamin may be partially regulated via the dephosphorylation of $\mathrm{I} \kappa \mathrm{B} \alpha$, without inhibition of AKT.

\section{Discussion}

In the present study, human ESCC cell lines (EC9706 and EC109) were treated with sporamin. The results demonstrated that sporamin suppressed the cell growth of ESCC cells in vitro, which may be mediated via NF- $\kappa \mathrm{B}$ inhibition. In addition, $\mathrm{NF}-\kappa \mathrm{B}$ DNA-binding activity, phosphorylation of $\mathrm{I} \kappa \mathrm{B} \alpha$ and nuclear expression of $\mathrm{NF}-\kappa \mathrm{B}$ were reduced in sporamin-treated ESCC cells.

To the best of our knowledge, the present study is the first to demonstrate that sporamin exhibits inhibitory effects on cell viability and proliferation in ESCC cells, and the inhibitory effects were positively associated with treatment duration and concentration. Apoptosis is a process that eliminates unwanted cells in various physiological processes. Dysregulation of apoptosis is implicated in carcinogenesis, and inhibition of cell viability and proliferation activity may indicate the induction of apoptosis (11). Therefore, the present study investigated whether apoptosis contributes to the inhibition of cell viability and proliferation following sporamin treatment in EC9706 and EC109 cells. Following sporamin treatment, EC9706 and EC109 cells exhibited features of apoptosis. Typical morphological features of apoptosis and percentages of apoptotic cells were demonstrated by DAPI nuclear staining and flow cytometric analysis, respectively. In addition, the results revealed that sporamin induced the downregulation of Bcl-2 and Bcl-XL protein expression, and upregulation of Bax protein levels. This indicates that sporamin may induce apoptosis via the regulation of Bcl-2, Bcl-XL and Bax protein expression.

As it is established that $N F-\kappa B$ enhances tumor cell growth via the regulation of $\mathrm{Bcl}-2$ and $\mathrm{Bcl}-\mathrm{XL}$ (10), the present study investigated whether sporamin may inhibit $N F-\kappa B$ DNA-binding activity using EMSA, and the results indicated that sporamin may suppress the cell growth of human ESCC cells, at least partially, via the inhibition of NF- $\kappa \mathrm{B}$ activation. $\mathrm{NF}-\kappa \mathrm{B}$ is a heterodimer consisting of p50 and p65 subunits, and, when inactive, is sequestered in the cytoplasm as it is bound to its endogenous inhibitor, $\mathrm{I} \kappa \mathrm{B}$, which consists of $\alpha$ and $\beta$ subunits $(12,13)$. I $\mathrm{B} \alpha$ is phosphorylated by the I $\mathrm{B}$ kinase complex, and this phosphorylation leads to the ubiquitination and subsequent degradation of $\mathrm{p}-\mathrm{I} \kappa \mathrm{B} \alpha$, which allows $\mathrm{NF}-\kappa \mathrm{B}$ to migrate from the cytoplasm to the nucleus, where it subsequently induces target gene expression $(12,13)$. In the present study, sporamin inhibited $\mathrm{NF}-\kappa \mathrm{B}$ activation, which may, at least partially, occur via reduced phosphorylation of $\mathrm{I} \kappa \mathrm{B} \alpha$.

$\mathrm{NF}-\kappa \mathrm{B}$ is additionally activated via various other signaling pathways (14). Of these, AKT signaling induces $\mathrm{NF}-\kappa \mathrm{B}$ activation in human hepatocellular carcinoma cells (15). Overexpression of EGFR and inactivation of the tumor suppressor gene phosphatase and tensin homolog may result in activation and/or expression of AKT and its downstream targets, including p70 pS6 kinase (16-18). However, in the present study, sporamin did not affect the expression and phosphorylation levels of AKT, or its downstream target p-p70 S6 kinase, indicating that sporamin may suppress cell growth of ESCC cells via an AKT-independent mechanism.

In conclusion, sporamin may inhibit cell viability and proliferation, and induce apoptosis in ESCC cells. In addition, inhibition of $\mathrm{NF}-\kappa \mathrm{B}$ activation was accompanied by reduced $\mathrm{Bcl}-2$ and $\mathrm{Bcl}-\mathrm{XL}$ expression, and increased $\mathrm{Bax}$ expression levels in sporamin-treated ESCC cells. A better understanding of the underlying mechanisms and further identification of additional downstream effectors of sporamin will help guide the development of more effective agents to treat human ESCC.

\section{Acknowledgements}

The present study was supported by grants from the Natural Science Foundation of Zhejiang Province (grant no. LY16H160033), the Public Welfare Technical Applied Research Project of Zhejiang Province (grant no. 2016C33189), the Science and Technology Plans of Taizhou City (grant no. 1701yw07), and the National College Students' Innovation and Entrepreneurship Training Program (grant no. 201710350008). 


\section{References}

1. Thrift AP: The epidemic of oesophageal carcinoma: Where are we now? Cancer Epidemiol 41: 88-95, 2016.

2. Ohashi S, Miyamoto S, Kikuchi O, Goto T, Amanuma Y and Muto M: Recent advances from basic and clinical studies of esophageal squamous cell carcinoma. Gastroenterology 149: $1700-1715,2015$.

3. Napier KJ, Scheerer M and Misra S: Esophageal cancer: A Review of epidemiology, pathogenesis, staging workup and treatment modalities. World J Gastrointest Oncol 6: 112-120, 2014.

4. Cowie A, Noble F and Underwood T: Strategies to improve outcomes in esophageal adenocarcinoma. Expert Rev Anticancer Ther 14: 677-687, 2014.

5. Li PG, Mu TH and Deng L: Anticancer effects of sweet potato protein on human colorectal cancer cells. World J Gastroenterol 19: 3300-3308, 2013.

6. Yao J and Qian C: Sporamin induce apoptosis in human tongue carcinoma cells by down-regulating Akt/GSK-3 signaling. Fundam Clin Pharmacol 25: 229-236, 2011.

7. Abdel-Latif MM, Kelleher D and Reynolds JV: Potential role of NF-kappaB in esophageal adenocarcinoma: As an emerging molecular target. J Surg Res 153: 172-180, 2009.

8. Ng HY, Ko JM, Yu VZ, Ip JC, Dai W, Cal S and Lung ML: DESC1, a novel tumor suppressor, sensitizes cells to apoptosis by downregulating the EGFR/AKT pathway in esophageal squamous cell carcinoma. Int J Cancer 138: 2940-2951, 2016.

9. Choi YJ, Moon KM, Chung KW, Jeong JW, Park D, Kim DH, Yu BP and Chung HY: The underlying mechanism of proinflammatory $\mathrm{NF}-\kappa \mathrm{B}$ activation by the mTORC2/Akt/IKK $\alpha$ pathway during skin aging. Oncotarget 7: 52685-52694, 2016.
10. Kim C, Cho SK, Kim KD, Nam D, Chung WS, Jang HJ, Lee SG, Shim BS, Sethi G and Ahn KS: $\beta$-Caryophyllene oxide potentiates $\mathrm{TNF} \alpha$-induced apoptosis and inhibits invasion through down-modulation of NF- $\mathrm{BB}$-regulated gene products. Apoptosis 19: 708-718, 2014.

11. Olechowska-Jarzab A, Ptak-Belowska A and Brzozowski T: Terapeutic importance of apoptosis pathways in pancreatic cancer. Folia Med Cracov 56: 61-70, 2016.

12. Fullard N, Wilson CL and Oakley F: Roles of c-Rel signalling in inflammation and disease. Int J Biochem Cell Biol 44: 851-860, 2012.

13. Kanarek N and Ben-Neriah Y: Regulation of NF- $\mathrm{kB}$ by ubiquitination and degradation of the IkBs. Immunol Rev 246: 77-94, 2012.

14. Ghosh S and Dass JF: Study of pathway cross-talk interactions with NF- $\kappa B$ leading to its activation via ubiquitination or phosphorylation: A brief review. Gene 584: 97-109, 2016.

15. Zhang G, Li Z, Wan X, Zhang Y,Zhu R, Liu Z,Ji D, Zhang H, Wu F, Tian H, et al: Repression of Human Hepatocellular Carcinoma Growth by Regulating Met/EGFR/VEGFR-Akt/NF- $\mathrm{B}$ Pathways with Theanine and Its Derivative, (R)-2-(6,8--Dibromo-2-oxo -2H-chromene-3-carboxamido)-5-(ethylamino)-5-oxopentanoic Ethyl Ester (DTBrC). J Agric Food Chem 64: 7002-7013, 2016.

16. Cooper JB and Cohen EE: Mechanisms of resistance to EGFR inhibitors in head and neck cancer. Head Neck 31: 1086-1094, 2009.

17. Yuge K, Kikuchi E, Hagiwara M, Yasumizu Y, Tanaka N, Kosaka T,Miyajima A and Oya M: Nicotine Induces tumor growth and chemoresistance through activation of the PI3K/Akt/mTOR pathway in bladder cancer. Mol Cancer Ther 14: 2112-2120, 2015.

18. Bussink J, van der Kogel AJ and Kaanders JH: Activation of the PI3-K/AKT pathway and implications for radioresistance mechanisms in head and neck cancer. Lancet Oncol 9: 288-296, 2008. 